\title{
Using DIRECT Wound Assessment to Predict Limb Salvage and Provide Prognosis of Diabetic Foot Ulcers
}

\author{
Dongkeun Jun (D), Yongseok Kwon (D), Jaehyun Bae (D), Myungchul Lee (D), Jeenam Kim (D), Hyungon Choi (D), \\ Donghyeok Shin (D) \\ Department of Plastic and Reconstructive Surgery, Konkuk University Medical Center, Seoul, Korea
}

Background: Many wound assessment systems including the Wagner classification and University of Texas (UT) grading system have been previously described. The authors of this study applied the DIRECT (Debridement of necrosis, Infection control, Revascularization, Exudate control, Chronicity, and Top surface) wound coding system for initial assessment of diabetic foot ulcers (DFUs) to predict limb salvage and prognosis.

Methods: From January 2016 to February 2020, a total of 169 first-time DFU patients were retrospectively evaluated using the DIRECT wound coding assessment system. DFUs were followed up for at least 6 months, and scores in each component of the coding system according to final limb status were statistically evaluated. The coding assessment's ability to predict major amputation was compared to those of the Wagner classification and the UT grading system.

Results: Subjects were divided into complete healing ( $n=80,47.3 \%)$, not healed $(n=71,42 \%)$, and amputation ( $n=18,10.7 \%)$ groups. The mean values of each component of DIRECT assessment for the complete healing/amputation groups were $D$ 0.86/1.56 $(P<0.001)$, I 0.46/0.89 ( $P=0.001$ ), R 0.65/0.94 ( $P=0.014), E$ 1.15/1.56 ( $P=0.049), C 0.69 / 0.89$ ( $P=0.086), T 0.53 / 0.72(P=0.13)$ and the sum was 3.140/4.741 $(\mathrm{P}<0.001)$. The area under the receiver operating characteristic curve of the DIRECT, Wagner, and UT grading systems was $0.722,0.603$, and 0.663 , respectively.

Conclusion: The DIRECT coding system shows a greater association with prediction of amputation or complete healing, compared with the Wagner and UT wound classification systems. This more accurate wound assessment system will be helpful in predicting prognosis and planning treatments.

Keywords: Amputation; Diabetic foot; Limb salvage; Wound healing

\section{Introduction}

Diabetic foot ulcer (DFU) is a type of chronic wound whose incidence has increased around the world with the growing numbers of diabetic patients. About $19 \%$ to $34 \%$ of diabetic patients will suffer from DFU in their lifetime [1]. Brownrigg et al. [2] reported that DFU healing rates at 1 year varied from $18 \%$ to $61 \%$, with major amputation rates ranging from $3 \%$ to $19 \%$. Depending on the patient's condition at the initial visit, physicians agonize between limb salvage and early amputation. While such decisions are usually made based on the clinicians' experience, it takes a significant amount of time for practitioners to gain expertise in wound care including assessment and management. An accurate initial wound assessment from the physician leads to a better treatment decision with faster results. As such, the importance of accurate initial wound assessments cannot be overstated [3].

Previous literature has described various wound assessment guidelines including the Wagner classification, University of Texas (UT) grading system, and the Perfusion, Extent, Depth, Infection and Sensation (PEDIS) grading classification system.

\section{Original Article}

Received: November 5, 2020

Revised: December 4, 2020

Accepted: December 5, 2020

\section{Corresponding author: Donghyeok Shin, M.D., Ph.D.}

Department of Plastic and Reconstructive Surgery, Konkuk University Medical Center, 120-1 Neungdong-ro, Gwangiin-gu, Seoul 05030, Korea

Tel: $+82-2-2030-7380$

Fax: +82-2-2030-5249

E-mail: sdhplastic@kuh.ac.kr

This is an Open Access article distributed under the terms of the Creative Commons Attribution Non-Commercia License (https://creativecommons org/licenses/by-nc/4 O/) which permits unrestricted non-commercial use, distribution, and reproduction in any medium, provided the original work is properly cited.

C) 2021 Korean Wound Management Society 
The Wagner classification system was the first framework to categorize DFUs. It assesses the depth of the ulcer and the presence of osteomyelitis or gangrene and divides the ulcers into six grades. Although it is simple to use and in wide application, it does not consider peripheral arterial disease and infection for the first three grades (0-2) [4]. Meanwhile, the UT system consists of grades and stages. Grades of DFUs are based on ulcer depth, and then the stages are determined by the presence or absence of infection and ischemia. The UT system helps predict outcomes because infection and ischemia are included in the evaluation. However, the grades and stages are not definitive in predicting the future state of the wound [5]. So far, neither have been widely accepted as a standardized method for DFU assessment [4].

Jun et al. [3] presented the DIRECT coding system as a simple, systematic, and standardized (3S) assessment tool for all types of wounds, that is easy to use for both experts and nonspecialist wound care providers. It consists of six components for assessment, and each component has its own pathophysiology affecting the wound healing process; Debridement of necrosis, Infection control, Revascularization, Exudate control, Chronicity, and Top surface, which are abbreviated into the acronym "DIRECT." We applied the DIRECT coding sys- tem to DFUs and analyzed the correlation between the DIRECT scores and clinical outcomes in patients with DFUs treated in a multidisciplinary setting, and afterwards compared the DIRECT coding system to the Wagner classification and UT grading system.

\section{Methods}

\section{Selection criteria}

A total of 462 patients with newly presented DFUs were retrospectively reviewed from January 2016 to February 2020. Patients with less than 6 months of follow-up or incomplete medical records were excluded $(n=293)$. The requirement for informed consent was waived, and this investigation was approved by the Institutional Review Board of Konkuk University Medical Center (IRB No. KUMC-2020-03-046). The study was conducted in accordance with the principles of the Helsinki Declaration.

\section{Wound assessment and assessment comparison}

All wounds of DFU were evaluated with the DIRECT coding system, the Wagner classification and UT grading system from the first visit (Fig. 1). The evaluation according to each assess-

\begin{tabular}{|c|c|c|c|c|c|c|c|c|c|}
\hline \multicolumn{10}{|c|}{$\begin{array}{l}\text { Wound No. } \\
\text { Wound type }\end{array}$} \\
\hline \multicolumn{2}{|c|}{ Diabetic foot ulcer } & Pressure ulcer & Icer & \multicolumn{2}{|c|}{ Traumatic wound } & $\square$ & \multicolumn{2}{|c|}{ Venous ulcer } & ㅁ \\
\hline \multicolumn{2}{|c|}{ Arterial ulcer } & Burn & $\square$ & \multicolumn{2}{|c|}{ Surgical suture wound } & $\square$ & \multicolumn{2}{|c|}{ Wound dehiscence } & $\square$ \\
\hline \multirow{2}{*}{\multicolumn{2}{|c|}{$\begin{array}{l}\text { Cancerous wound } \\
\text { Location }\end{array}$}} & Scar & $\square$ & \multicolumn{2}{|l|}{ others } & $\square$ & \multirow{2}{*}{\multicolumn{2}{|c|}{1}} & ) \\
\hline & & & - . & \multicolumn{2}{|c|}{. } & & & & \\
\hline & $-x_{-}$ & $\mathrm{cm}$ & & & & & & \\
\hline \multicolumn{2}{|c|}{ Debridement of necrosis } & DO 口 & D1 (dry) $\square \quad D^{2}$ & D2 (wet) $\square$ & \multirow{2}{*}{\multicolumn{2}{|c|}{$75 \sim 100 \% \square$}} & & & \\
\hline & Amount & $<25 \% \square$ & $25 \sim 50 \% \square$ & $50 \sim 75 \% \square$ & & & & & \\
\hline \multirow[t]{5}{*}{ Infectior } & & $10 \square$ & I1 $\square$ & & & & & & \\
\hline & Severity & Mild $\square \quad N$ & Moderate $\square$ & Severe $\square$ & & & & & \\
\hline & Local Sx/Sign & Erythema $\square$ & Pain $\square$ & Tenderness $\square$ & \multicolumn{2}{|c|}{ Warmth $\square$} & & & \\
\hline & Extension & $\leq 2 \mathrm{~cm} \square$ & $>2 \mathrm{~cm} \square$ & & & & & & \\
\hline & Odor & $Y \square$ & $\mathrm{N} \square$ & & & & & & \\
\hline \multicolumn{2}{|c|}{ Revascularization } & Ro $\square$ & R1 $\square$ & Jndetermined $\square$ & & & & & \\
\hline Exudat & & EO $\square$ & E1 $\square$ & E3 $\square$ & & & & & \\
\hline & & Bloody $\square$ & Serosanguin & ineous $\square$ & Serous $\square$ & Puru & Alent $\square$ & & \\
\hline & Color & & 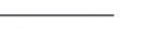 & & & & & & \\
\hline Chronic & & CO $\square$ & C1 $\square$ & & & & & & \\
\hline & & ( ) M & ()$W$ & ) $D$ & & & & & \\
\hline Top sur & & TO $\square$ & T1 $\square$ & & & & & & \\
\hline & Depth & Partial thickr & kness skin $\square$ & Full thickness & skin $\square$ & Sub $Q$ & 2 व & Deep fascia $\square$ & \\
\hline & & Muscle $\square$ & Tendon $\square$ & Bone $\square$ & Joint $\square$ & OM & & Undetermined $\square$ & \\
\hline & Undermining & $\mathrm{Y} \square$ & -cm & & & & & & \\
\hline & Peripheral tissue & Edema $\square$ & Induration $\square$ & & & & & & \\
\hline & Granulation & $<25 \% \square$ & $25 \sim 50 \% \square$ & $50 \sim 75 \% \square$ & $75 \sim 1$ & $0 \% \square$ & & & \\
\hline & Epithelialization & $\mathrm{Y} \square$ & $\mathrm{N} \square$ & & & & & & \\
\hline Photo & Taken? & $\mathrm{Y} \square$ & $N \square$ & & & & & & \\
\hline Assessr & & $\mathrm{D} \square \mathrm{I} \square \mathrm{R} \square$ & $\mathrm{E} \square \mathrm{C} \square \mathrm{T} \square$ & & & & & & \\
\hline
\end{tabular}

Fig. 1. The DIRECT coding system form used in our clinic. DIRECT, Debridement of necrosis, Infection control, Revascularization, Exudate control, Chronicity, and Top surface. 
ment framework was conducted by a single investigator, based on physical examinations and clinical photos. Weekly DFU evaluations were conducted with each component of the DIRECT coding system, and treatment was modified accordingly. The evaluation continued until the total score reached 0 , which means complete healing. Participants' characteristics, laboratory results, and final limb status were evaluated. Various treatment techniques including serial dressing treatment, split thickness skin graft, toe amputation, negative pressure wound therapy, and free flap coverage were performed. The DIRECT scoring definitions and management protocols are described in Table 1. DFUs were followed up for at least 6 months, and the outcomes were classified into complete healing, not healed, or amputation according to the final state (Fig. 2). The "not healed" group was defined as patients whose wounds remained in spite of more than 6 months' treatment, and the "amputation" group indicated major amputation above ankle level, i.e., above- or below-knee.

In the DIRECT coding system, a total score was obtained according to the following formula to account for the different maximum value in each category; a total score exceeding 5 was considered a high risk of amputation.

$$
\text { Sum }=\mathrm{D} / 2+\mathrm{I}+\mathrm{R}+\mathrm{E} / 3+\mathrm{C}+\mathrm{T}
$$

The Wagner classification system assesses the depth of the ulcer and the presence of osteomyelitis or gangrene with the following grades: grade 0 (intact skin), grade 1 (superficial ulcer of skin or subcutaneous tissue), grade 2 (ulcers extend into tendon, bone, or capsule), grade 3 (deep ulcer with osteomyelitis, or abscess), grade 4 (partial foot gangrene), and grade 5 (whole foot gangrene). Grades 4 and 5 were assumed to affect the possibility of amputation, because gangrene is present and is usually due to a combination of ischemia and infection [4].

The UT system grades DFUs by ulcer depth, and the stages are determined by the presence or absence of infection and ischemia: grade 0 (pre- or post-ulcerative site that has healed), grade 1 (superficial wound not involving tendon, capsule, or bone), grade 2 (wound penetrating to tendon or capsule), grade 3 (wound penetrating bone or joint); and stage $\mathrm{A}$ (clean wounds), stage B (non-ischemic infected wounds), stage C (ischemic non-infected wounds) and stage D (ischemic infected wounds). Patients with ischemic ulcers (stages C and D)

Table 1. DIRECT scoring definitions and management protocols

\begin{tabular}{|c|c|c|}
\hline Category & Definition & Management protocol \\
\hline \multirow[t]{3}{*}{ Need for Debridement } & D0 (no necrotic tissue) & Regular follow-up \\
\hline & D1 (dry necrosis) & Debridement after revascularization \\
\hline & $\begin{array}{l}\text { D2 (wet necrosis, white or yellow, sticky and sloughy } \\
\text { tissue) }\end{array}$ & Sufficient debridement to remove dead and infected tissues \\
\hline \multirow[t]{2}{*}{ Need to Infection control } & 10 (no sign of infection) & Dressing guided by the status of the other categories \\
\hline & I1 (bacteria or fungi proliferate around the wound) & Adequate debridement and systemic antibiotics \\
\hline \multirow[t]{2}{*}{ Need for Revascularization } & R0 (no abnormality in blood flow) & Usually verified with CT angiography \\
\hline & R1 (arterial or venous insufficiency in the extremity vessel) & Revascularization procedures such as PTA or bypass surgery \\
\hline \multirow[t]{4}{*}{ Need for Exudate control } & EO (no exudate is released) & \multirow{4}{*}{$\begin{array}{l}\text { Sufficient absorption with proper debridement and infection } \\
\text { control }\end{array}$} \\
\hline & E1 (once-daily 2 mm-foam dressing) & \\
\hline & E2 (once-daily 5 mm-foam dressing) & \\
\hline & E3 (twice or more-daily $5 \mathrm{~mm}$-foam dressing) & \\
\hline \multirow[t]{2}{*}{ Defining the Chronicity of the wound } & $\begin{array}{l}\mathrm{CO} \text { (healed within } 2 \text { weeks or healing progress is seen } \\
\text { with the wound treatment) }\end{array}$ & $\begin{array}{l}\text { Prevent diffusion of any infection to surrounding tissues } \\
\text { through immediate drainage and repetitive debridement }\end{array}$ \\
\hline & $\begin{array}{l}\mathrm{C} 1 \text { (no visible healing progress even after } 3 \text { to } 6 \text { weeks } \\
\text { of active treatment) }\end{array}$ & $\begin{array}{l}\text { Evaluate the wound based on the DIRECT coding system and } \\
\text { treat the causes of the incomplete recovery as } \\
\text { indicated }\end{array}$ \\
\hline \multirow[t]{2}{*}{ Condition of the Top surface of the skin } & T0 (open only a little or not at all) & $\begin{array}{l}\text { Sufficient moisturization, trimming calluses on a regular } \\
\text { basis }\end{array}$ \\
\hline & T1 (the inside of the skin is exposed) & Appropriate closure of open wounds \\
\hline
\end{tabular}

DIRECT, Debridement of necrosis, Infection control, Revascularization, Exudate control, Chronicity, and Top surface; CT, computed tomography; PTA, percutaneous transluminal angioplasty. 


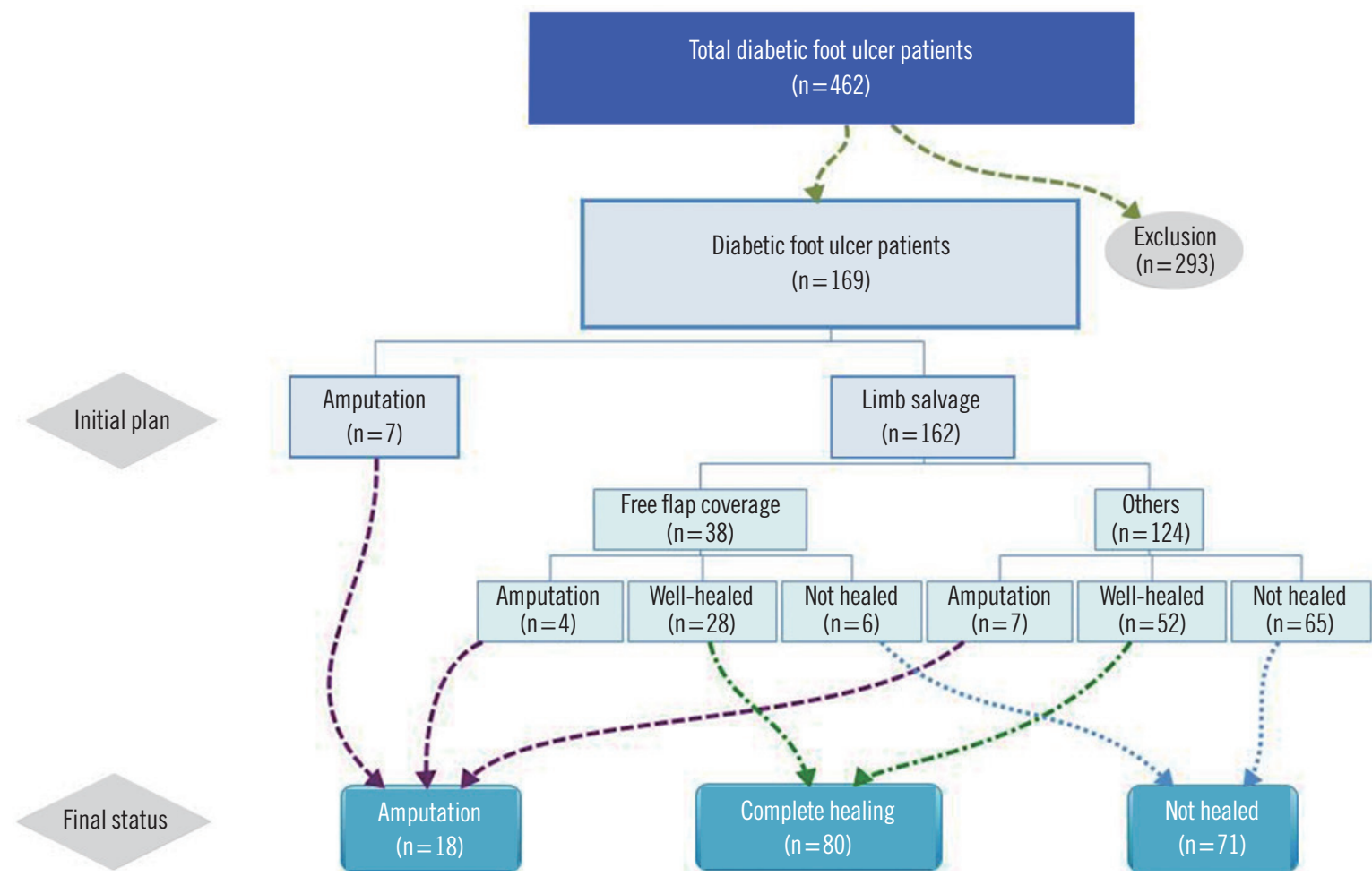

Fig. 2. Patient distribution and outcomes. A total of 462 patients with first-time diabetic foot ulcers from January 2016 to February 2020 were retrospectively reviewed. Patients who followed up for less than 6 months or those with incomplete medical records were excluded ( $n=293$ ). The final results were classified as complete healing, not healed, and amputation.

and higher grades were three times more likely to progress to amputation when compared with patients with non-ischemic ulcers (stages A and B) [4]. Therefore, patients with stage C3 or D3 DFUs were assessed to be more likely to undergo amputation.

In this study, the scores in each component of the DIRECT coding system according to final limb status were statistically evaluated. In order to compare the predictability of major amputation, the implications of the increase in scores in each assessment system were statistically compared and analyzed. A total score exceeding 5 from the DIRECT system, grades 4 or 5 from the Wagner classification, and C3 or D3 from the UT classification were also comparatively analyzed as predictive of high possibility of major amputations. In this process, the "not healed" group $(n=71)$ was excluded from the comparison because their final limb salvage results were undetermined.

\section{Statistical analyses}

Statistical analysis was performed with SPSS Statistics for Windows version 17 (SPSS Inc., Chicago, IL, USA). The results are expressed as mean \pm standard deviation or percentages (\%). Chi-square test, Kruskal-Wallis test, Fisher exact test, Mann-
Whitney $\mathrm{U}$ test, and logistic regression analysis were used to compare the variables, and a value of $\mathrm{P}<0.05$ was considered to be statistically significant. The receiver operating characteristic (ROC) curve and the areas under the curve (AUC) were used for further comparative analysis of limb salvage predictions from the three wound assessment systems.

\section{Results}

A total of 169 patients with first diagnosis of DFUs were included in the final analysis. Table 2 shows the baseline demographic details and DFU characteristics at first presentation. The outcomes after a mean follow-up of 10.6 months (range, 6-46 months) were classified as complete healing $(n=80$, $47.3 \%)$, not healed $(n=71,42 \%)$, and amputation $(n=18$, $10.7 \%$ ). Analysis of variables indicated that comorbidity with hypertension, peripheral arterial occlusive disease, end stage renal disease, weight-bearing location of wound, larger size of wound $\left(\mathrm{cm}^{2}\right)$, time from wound occurrence to outpatient visit (day), high C-reactive protein $(\mathrm{mg} / \mathrm{dL})$, poor ankle brachial index, and revascularization failure were statistically significant predictors of amputation. The patients' demographics and 
Jun $D$ et al.

DIRECT assessment in diabetic foot

Table 2. Patient demographics

\begin{tabular}{|c|c|c|c|c|}
\hline Variable & Complete healing $(n=80)$ & Not healed $(n=71)$ & Amputation $(n=18)$ & P-value \\
\hline Sex & & & & $0.553^{\mathrm{a})}$ \\
\hline Male & $60(75.0)$ & $48(67.6)$ & $12(66.7)$ & \\
\hline Female & $20(25.0)$ & $23(32.4)$ & $6(33.3)$ & \\
\hline Mean age (yr) & $69.04 \pm 11.85$ & $66.49 \pm 11.67$ & $64.39 \pm 12.94$ & $0.200^{\mathrm{b})}$ \\
\hline $\mathrm{BMI}\left(\mathrm{kg} / \mathrm{m}^{2}\right)$ & $24.19 \pm 3.67$ & $24.66 \pm 3.66$ & $24.22 \pm 3.56$ & $0.421^{\mathrm{b})}$ \\
\hline \multicolumn{5}{|l|}{ Comorbidity } \\
\hline Hypertension & $53(66.3)$ & $51(71.8)$ & $17(94.4)$ & $0.043^{\mathrm{c}, \mathrm{d})}$ \\
\hline Coronary artery disease & $24(30.0)$ & $22(31.0)$ & $10(55.6)$ & $0.101^{\text {a) }}$ \\
\hline Peripheral arterial occlusive disease & $48(60.0)$ & $37(52.1)$ & $17(94.4)$ & $0.002^{\mathrm{c}, \mathrm{d})}$ \\
\hline End stage renal disease & 17 (21.3) & $19(26.8)$ & $10(55.6)$ & $0.013^{\mathrm{a}, \mathrm{d})}$ \\
\hline Osteomyelitis & $10(12.5)$ & $13(18.3)$ & $5(27.8)$ & $0.253^{\text {a) }}$ \\
\hline Wound location & & & & $0.029^{(c), d)}$ \\
\hline Weight bearing area & $53(66.3)$ & $60(84.5)$ & $14(77.8)$ & \\
\hline Non weight bearing area & $27(33.8)$ & $11(15.5)$ & $4(22.2)$ & \\
\hline Wound size $\left(\mathrm{cm}^{2}\right)$ & $24.58 \pm 36.35$ & $18.53 \pm 24.07$ & $72.28 \pm 50.19$ & $<0.001^{\mathrm{b}, \mathrm{d})}$ \\
\hline Wound days & $56.71 \pm 53.87$ & $113.34 \pm 53.95$ & $91.67 \pm 106.22$ & $<0.001^{\mathrm{b}, \mathrm{d})}$ \\
\hline \multicolumn{5}{|l|}{ Laboratory results } \\
\hline Hemoglobin (g/dL) & $10.84 \pm 1.97$ & $11.42 \pm 2.44$ & $10.54 \pm 1.69$ & $0.281^{\mathrm{bl}}$ \\
\hline Hematocrit (\%) & $31.95 \pm 5.51$ & $33.47 \pm 6.60$ & $31.38 \pm 4.70$ & $0.338^{\mathrm{b})}$ \\
\hline $\mathrm{HbAlc}(\%)$ & $8.24 \pm 2.31$ & $8.45 \pm 2.24$ & $8.05 \pm 2.07$ & $0.728^{\mathrm{b})}$ \\
\hline White blood cells $\left(\times 10^{3} / \mu \mathrm{L}\right)$ & $8.89 \pm 3.97$ & $10.05 \pm 5.29$ & $13.24 \pm 7.70$ & $0.113^{\mathrm{b})}$ \\
\hline C-reactive protein (mg/dL) & $5.19 \pm 7.28$ & $4.87 \pm 6.79$ & $11.12 \pm 8.37$ & $0.003^{\mathrm{b}, d)}$ \\
\hline Erythrocyte sedimentation rate $(\mathrm{mm} / \mathrm{hr})$ & $54.32 \pm 37.57$ & $51.17 \pm 32.46$ & $64.33 \pm 33.97$ & $0.365^{\mathrm{bl}}$ \\
\hline Albumin (g/dL) & $3.57 \pm 0.55$ & $3.74 \pm 0.50$ & $3.38 \pm 0.76$ & $0.125^{b)}$ \\
\hline Viscosity (systolic) (cP) & $3.89 \pm 0.75$ & $4.01 \pm 0.96$ & $4.28 \pm 0.98$ & $0.312^{\mathrm{b})}$ \\
\hline Viscosity (diastolic) (cP) & $12.00 \pm 3.80$ & $12.24 \pm 3.92$ & $13.64 \pm 4.51$ & $0.311^{\mathrm{b})}$ \\
\hline Ankle brachial index & $1.01 \pm 0.19$ & $0.96 \pm 0.19$ & $0.75 \pm 0.21$ & $<0.001^{\mathrm{b}, \mathrm{d})}$ \\
\hline CT angiogram & & & & $0.057^{c)}$ \\
\hline Unexamined & $9(11.3)$ & $3(4.2)$ & 0 & \\
\hline Stenosis on CT angiogram & $48(60.0)$ & $38(53.5)$ & $15(83.3)$ & \\
\hline Patent arteries on CT angiogram & $23(28.8)$ & $30(42.3)$ & $3(16.7)$ & \\
\hline Revascularization & & & & $0.001^{\mathrm{c}, \mathrm{d})}$ \\
\hline Undetermined & $9(11.3)$ & $3(4.2)$ & 0 & \\
\hline Succeeded & $68(85.0)$ & $56(78.9)$ & $11(61.1)$ & \\
\hline Failed & $3(3.8)$ & $12(16.9)$ & $7(38.9)$ & \\
\hline
\end{tabular}

Values are presented as number (\%) or mean \pm SD.

BMI, body mass index; HbAlc, glycated hemoglobin A; CT, computed tomography.

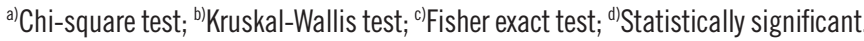

other comorbidities were otherwise similar between groups $(\mathrm{P}<0.05)$ (Table 2).

The final assessment results of each group under the three wound classification systems are shown in Table 3 . The mean scores for each component from the DIRECT assessment for Complete healing/Amputation group were D 0.86/1.56 ( $\mathrm{P}<$ 
Jun $D$ et al.

DIRECT assessment in diabetic foot

Table 3. Comparison of wound assessment across three wound classification systems

\begin{tabular}{|c|c|c|c|}
\hline Variable & Complete healing $(n=80)$ & Not healed $(n=71)$ & Amputation $(n=18)$ \\
\hline \multicolumn{4}{|c|}{ DIRECT wound assessment } \\
\hline \multicolumn{4}{|c|}{ Debridement of necrosis } \\
\hline DO & $25(71.4)$ & $9(25.7)$ & $1(2.9)$ \\
\hline D1 & $41(66.1)$ & $15(24.2)$ & $6(9.7)$ \\
\hline D2 & $14(19.4)$ & $47(65.3)$ & $11(15.3)$ \\
\hline \multicolumn{4}{|l|}{ Infection } \\
\hline 10 & $43(76.8)$ & $11(19.6)$ & $2(3.6)$ \\
\hline I1 & $37(32.7)$ & $60(53.1)$ & $16(14.2)$ \\
\hline \multicolumn{4}{|c|}{ Revascularization } \\
\hline Ro & $28(71.8)$ & $10(25.6)$ & $1(2.6)$ \\
\hline R1 & $52(40.0)$ & $61(46.9)$ & $17(13.1)$ \\
\hline \multicolumn{4}{|l|}{ Exudate } \\
\hline E0 & $14(73.7)$ & $3(15.8)$ & $2(10.5)$ \\
\hline $\mathrm{E} 1$ & $42(66.7)$ & $15(23.8)$ & $6(9.5)$ \\
\hline E2 & $22(29.7)$ & $44(59.5)$ & $8(10.8)$ \\
\hline E3 & $2(15.4)$ & $9(69.2)$ & $2(15.4)$ \\
\hline \multicolumn{4}{|l|}{ Chronicity } \\
\hline $\mathrm{CO}$ & $25(86.2)$ & $2(6.9)$ & $2(6.9)$ \\
\hline $\mathrm{Cl}$ & $55(39.3)$ & $69(49.3)$ & $16(11.4)$ \\
\hline \multicolumn{4}{|c|}{ Top surface } \\
\hline T0 & $38(67.9)$ & $13(23.2)$ & $5(8.9)$ \\
\hline $\mathrm{T} 1$ & $42(37.2)$ & $58(51.3)$ & $13(11.5)$ \\
\hline Suma) & $3.14 \pm 1.52$ & $4.87 \pm 1.25$ & $4.74 \pm 0.99$ \\
\hline \multicolumn{4}{|c|}{ Wagner classification } \\
\hline Grade 0 & $7(77.8)$ & $2(22.2)$ & 0 \\
\hline Grade 1 & $32(72.7)$ & $8(18.2)$ & $4(9.1)$ \\
\hline Grade 2 & $12(35.3)$ & $18(52.9)$ & $4(11.8)$ \\
\hline Grade 3 & $10(22.2)$ & $33(73.3)$ & $2(4.4)$ \\
\hline Grade 4 & $19(54.3)$ & $10(28.6)$ & $6(17.1)$ \\
\hline Grade 5 & 0 & 0 & $2(100)$ \\
\hline \multicolumn{4}{|c|}{ UT classification } \\
\hline \multicolumn{4}{|l|}{ Stage A } \\
\hline Grade 0 & $8(88.9)$ & $1(11.1)$ & 0 \\
\hline Grade 1 & $12(85.7)$ & $2(14.3)$ & 0 \\
\hline Grade 2 & $1(100)$ & 0 & 0 \\
\hline Grade 3 & $2(100)$ & 0 & 0 \\
\hline \multicolumn{4}{|l|}{ Stage B } \\
\hline Grade 0 & 0 & 0 & 0 \\
\hline Grade 1 & $8(50.0)$ & $8(50.0)$ & 0 \\
\hline Grade 2 & $4(44.4)$ & $5(55.6)$ & 0 \\
\hline Grade 3 & $2(18.2)$ & $9(81.8)$ & 0 \\
\hline
\end{tabular}


Table 3. Continued

\begin{tabular}{cccc}
\hline Variable & Complete healing $(n=80)$ & Not healed $(n=71)$ & Amputation $(n=18)$ \\
\hline Stage C & 0 & & 0 \\
Grade 0 & $16(69.6)$ & $1(100)$ & $1(4.3)$ \\
Grade 1 & $3(60.0)$ & $2(26.1)$ & 0 \\
Grade 2 & $4(30.8)$ & $6(46.2)$ & $3(23.1)$ \\
Grade 3 & & & 0 \\
Stage D & 0 & 0 & $6(37.5)$ \\
Grade 0 & $6(37.5)$ & $4(25.0)$ & $2(14.3)$ \\
Grade 1 & $4(28.6)$ & $8(57.1)$ & $6(17.1)$ \\
Grade 2 & $10(28.6)$ & $19(54.3)$ & \\
Grade 3 & & \\
\hline
\end{tabular}

Values are presented as number (\%) or mean \pm SD.

DIRECT, Debridement of necrosis, Infection control, Revascularization, Exudate control, Chronicity, and Top surface; UT, University of Texas.

${ }^{\text {a) }}$ Sum $=\mathrm{D} / 2+\mathrm{I}+\mathrm{R}+\mathrm{E} / 3+\mathrm{C}+\mathrm{T}$.

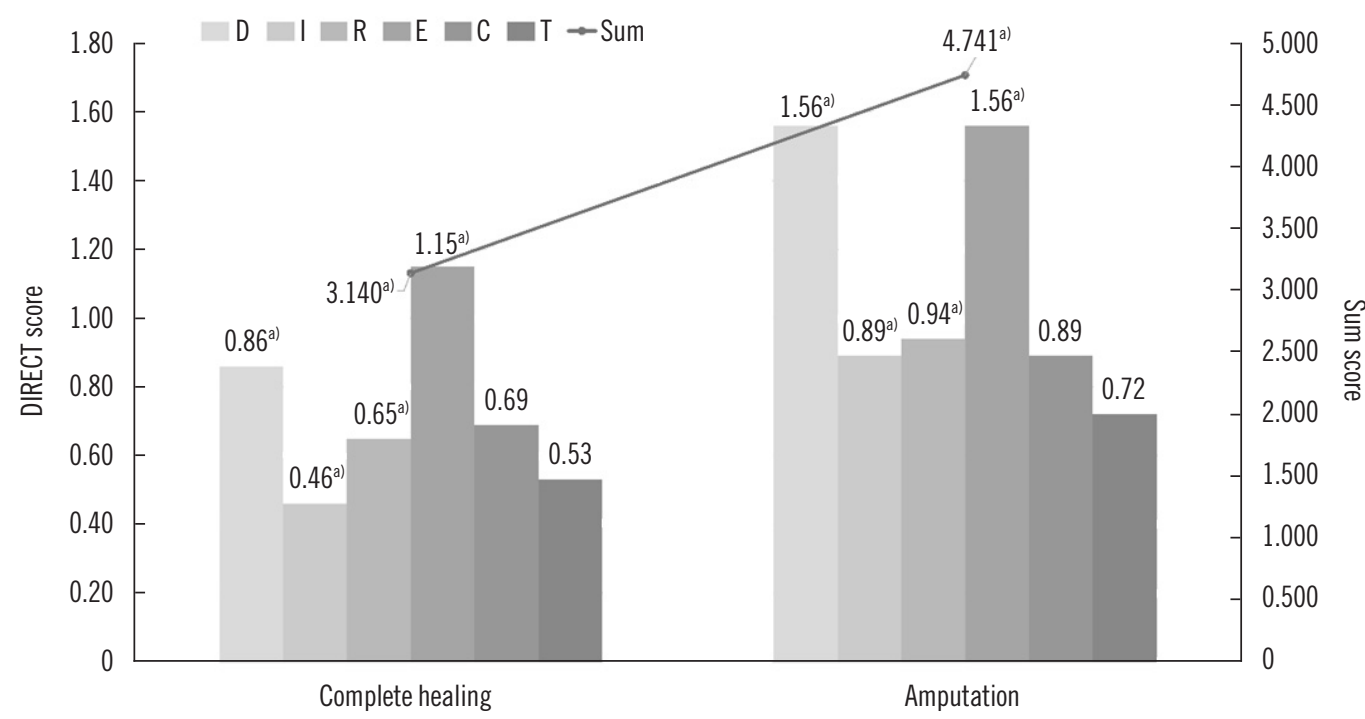

Fig. 3. Comparison of DIRECT scores for limb salvage and amputation groups. The horizontal axis indicates the Debridement of necrosis, Infection control, Revascularization, Exudate control, Chronicity, and Top surface (DIRECT) components for the complete healing group and amputation group. The mean values of each component score are indicated on the left vertical axis, and the sum of DIRECT scores for complete healing and amputation group, respectively, are shown on the right. In the amputation group, the score of

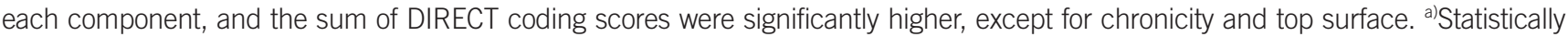
significant according to the results of the Mann-Whitney $U$ test $(P<0.05)$.

0.001), I 0.46/0.89 (P=0.001), R 0.65/0.94 (P=0.014), E 1.15/1.56 $(\mathrm{P}=0.049), \mathrm{C} 0.69 / 0.89(\mathrm{P}=0.086), \mathrm{T} 0.53 / 0.72(\mathrm{P}=0.13)$; and the total sum was 3.140/4.741 ( $\mathrm{P}<0.001)$ (Fig. 3). According to the results of the Mann-Whitney $U$ test, the score of each component and sum of the DIRECT assessment were significantly higher $(\mathrm{P}<0.05)$ in amputation groups, except for chronicity and top surface.
On logistic regression analysis, an increase of 1 on the sum of the DIRECT coding system increased the odds of amputation by 2.795 , whereas an increase of 1 on the Wagner classification increased the odds of amputation by $1.571(\mathrm{P}=0.022)$. In the UT classification system, the odds of amputation increased by $5.718(\mathrm{P}=0.001)$ as the stage changed from $\mathrm{A}$ to $\mathrm{D}$ and by $1.906(\mathrm{P}=0.02)$ as the grade increased by 1 . 
Finally, in the DIRECT coding system, the area under the ROC curve (AUC) was 0.722 (95\% confidence interval [CI], 0.622-0.807). In comparison, the ROC curves of the Wagner and UT classification systems had an AUC of 0.603 (95\% CI, $0.500-0.701)$ and 0.663 (95\% CI, 0.560-0.755), respectively (Table 4, Fig. 4).

\section{Case}

A 61-year-old male patient visited our clinic with a DFU, reporting its onset as 2 months earlier (Fig. 5A). The DFU was covered with partially wet necrotic tissue, and there was redness, heating sensation, and foul odor, and much discharge was observed, suggesting inflammation and infection. The initial assessment was grade 4 on the Wagner classification, D3 on the UT classification, and D2 I1 R1 E2 C1 T0 on the DIRECT coding system. The Wagner and UT classifications sug-

Table 4. Comparative analysis of limb salvage prediction across three wound assessment systems by area under the ROC curve

\begin{tabular}{lccc}
\hline Variable & $\begin{array}{c}\text { Area under the } \\
\text { ROC curve }\end{array}$ & $\begin{array}{c}\text { Standard } \\
\text { error }\end{array}$ & $95 \% \mathrm{Cl}$ \\
\hline DIRECT coding system & 0.722 & 0.0628 & $0.622-0.807$ \\
UT classification system & 0.663 & 0.0643 & $0.560-0.755$ \\
Wagner classification system & 0.603 & 0.0648 & $0.500-0.701$ \\
\hline
\end{tabular}

ROC, Receiver Operating Characteristic; Cl, confidence interval; DIRECT, Debridement of necrosis, Infection control, Revascularization, Exudate control, Chronicity, and Top surface; UT, University of Texas. gested a high probability of major amputation, whereas the DIRECT coding system projected limb salvage. In fact, the patient had been recommended below-knee amputation at another clinic before visiting our hospital. For 2 weeks, we performed wound management, including amputation of the fifth

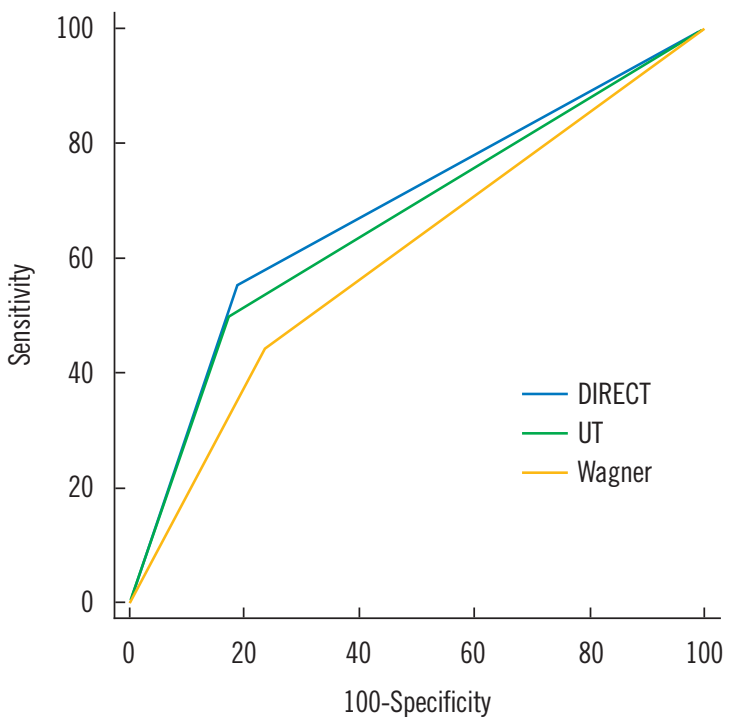

Fig. 4. Receiver operating characteristic curves for predicting outcomes. The Debridement of necrosis, Infection control, Revascularization, Exudate control, Chronicity, and Top surface (DIRECT) coding system showed a greater association with prediction of amputation or complete healing, compared with the Wagner and University of Texas (UT) wound classification systems.
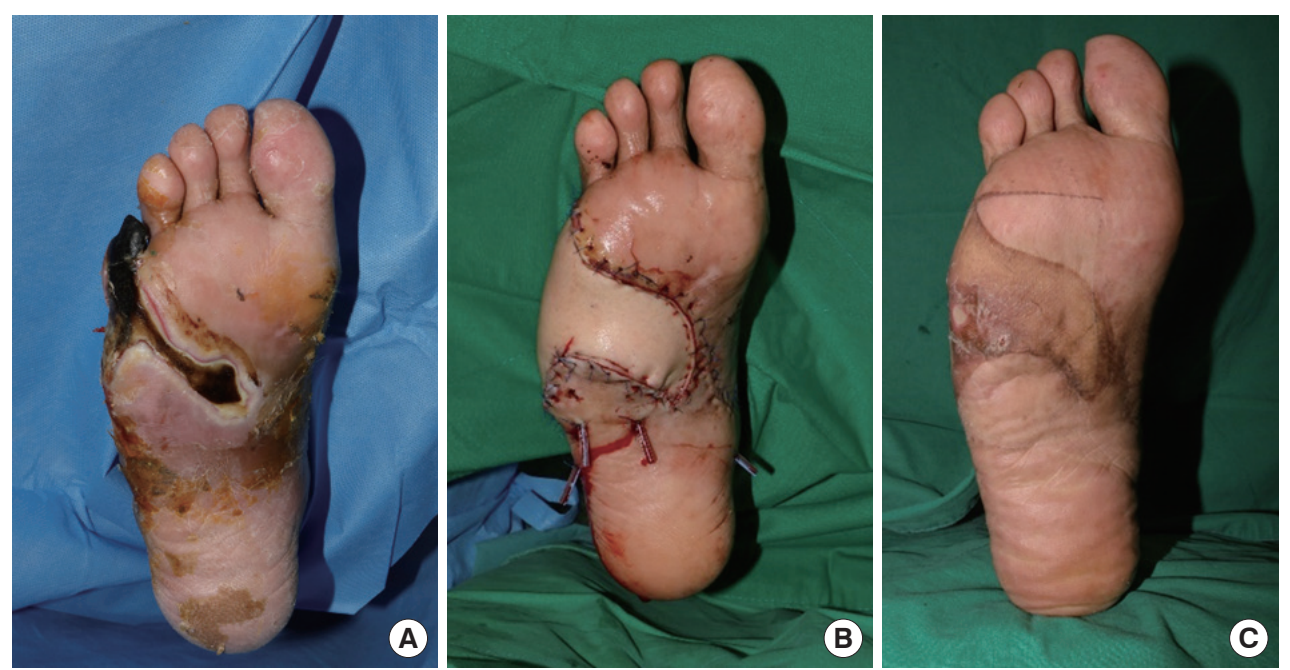

Fig. 5. Clinical photos of case: limb salvage by free flap transfer. (A) The initial wound of a diabetic foot ulcer. The Wagner and University of Texas (UT) classifications indicated a high probability of major amputation, whereas the Debridement of necrosis, Infection control, Revascularization, Exudate control, Chronicity, and Top surface (DIRECT) coding system projected limb salvage. The initial assessment was grade 4 on the Wagner classification, D3 on the UT classification, and D2 I1 R1 E2 C1 T0 on the DIRECT coding system. (B) Clinical photo after anterolateral thigh free flap coverage. (C) The well-healed wound is observed 6 months postoperatively. 
toe and removal of necrotic tissue until normal healthy tissue emerged. At the same time, computed tomography angiography was conducted to evaluate vascular compromise of the lower extremity. Mild stenosis of the right distal superficial femoral artery was observed and revascularization was accomplished through percutaneous transluminal angioplasty (PTA). After wound bed preparation and revascularization, reconstructive surgery was performed with an anterolateral thigh free flap (Fig. 5B). The wound was completely healed, and the foot was successfully salvaged 6 months after the surgery (Fig. 5C).

\section{Discussion}

One of the serious complications of diabetes is a DFU, which can threaten the life expectancy of patients. In some studies, mortality rates associated with a DFU are about $5 \%$ in the first year, and 5-year mortality rates are as high as $42 \%$ [6]. Treatment of DFU starts with strict control of blood glucose level, adequate arterial supply, and wound management $[7,8]$. If treatment is insufficient, unhealed ulcers may result in major amputations and degrade the patient's quality of life. A clear, objective guideline or algorithm based on pathophysiological factors is needed to determine optimal treatment. An initial assessment of the wound is important for predicting the prognosis and planning the treatment [2]. The DIRECT coding system was presented through a mobile application, "D+ wound solution," as a simple, systematic, and standardized algorithm enabling clinicians to grade all kinds of wounds and to provide proper management of the wound [3]. This is especially valuable for a clinician who has not much experience with DFU patients and may not be an expert on wound management. In fact, we lectured the DIRECT coding system to medical students for the past 4 years and then asked them to evaluate various wounds. Their results turned out to be similar to independent evaluations by plastic surgeons.

In this study, we found that a higher stage and grade of the Wagner and UT wound classification systems was associated with an increased risk of amputation. Oyibo et al. [4] reported that the stage of the UT system is a better predictor of outcomes than the Wagner system, and we also found this to be true. The Wagner classification is based on wound depth and necrosis, while the UT classification assesses the wound depth and the presence of infection and lower extremity ischemia. In short, ischemia and infection are not included in the Wagner classification, while the UT system does not include necrotic status and the size of the ulcer. Given the lack of statistical significance of the chronicity $(\mathrm{C})$ and the top surface $(\mathrm{T})$ in the DIRECT coding system, it can be assumed that neither component would have much effect on limb salvage of DFUs. Nevertheless, in general, conversion from a chronic to an acute wound is necessary to restart the healthy healing process. Reviewing the top surface also helps identify potential problems of the closed skin such as bruising, hematoma, seroma, or pus pockets under the subcutaneous layer, which are not immediately visible [3].

The DIRECT coding system showed a greater association with prediction of amputation or complete healing, compared with the Wagner and UT wound classification systems. The system, which combines six wound healing components, is more descriptive than other methods and provides detailed grading based on the wound status, allowing clinicians to easily track progression or regression. Furthermore, the system covers critical physiological points important for wound healing, such as vascular status, while the other systems focus on limited wound information. Finally, the theoretical basis of the system is more specific and straightforward, and its application is user-friendly.

The DIRECT coding system is designed to provide an understanding of the status of the wound and suggest the most practical treatment for wound care providers, including lessexperienced practitioners. Each component of the DIRECT coding system requires practitioners to review the wound, which is conducive to planning the treatment [3]. For example, debridement of necrotic tissues can promote recovery by converting a chronic wound to an acute wound [9]. In our study, the higher the D score, the higher the amputation rate was. Next, infection control was evaluated based on clinical findings of the wound such as pain, erythema, edema, increased exudate, odor, heat, and tenderness. Infection prolongs the inflammatory phase, interfering with wound healing by suppressing collagen deposition, contraction, and epithelization [10]. Meanwhile, the presence of ischemia increased the risk of amputation, which is assessed by the $\mathrm{R}$ component of the DIRECT coding system [4]. Adequate circulation is necessary for wound healing. However, diabetic patients tend to have poor vascular supply due to advanced atherosclerosis. In our study, the fact that there was no significant difference in chronicity between groups is thought to be due to this underlying state. Therefore, the vascular supply in diabetic patients must be assessed prior to wound care. If there is a stenosis or occlusion on angiography, revascularization through PTA or 
bypass surgery may be necessary. Having a patent artery means a higher likelihood of limb salvage [11]; conversely, without revascularization, wound healing will be delayed and will further complicate the decision of treatment method.

Since this study is a comparison of subjective evaluations conducted by a single investigator, there is potential risk of a systemic bias, and the results of this study may also have been influenced by the excluded non-healed group when comparing the three different assessments for prediction of limb salvage. In addition, the data collected from a single hospital does not represent global treatment practices and may include selection bias. Multicenter studies should be performed on larger samples; prospective studies will increase the validity of the results.

Nevertheless, the DIRECT coding system reflects variables that are strongly associated with the final outcome of DFUs and key factors for increasing the chance of successful reconstruction. It is a useful tool for predicting outcomes and determining treatment methods for DFUs, showing a higher association with prediction of amputation or complete healing compared to the Wagner and the UT wound classification systems. Tracking of progression or regression of wound healing will aid in more accurate predictions of outcomes. Future studies should include continuous periodic evaluation of the DIRECT scores with more frequent treatments at regular intervals as each component value moves towards 0 .

\section{Conflict of interest}

No potential conflict of interest relevant to this article was reported.

\section{ORCID iDs}

$\begin{array}{ll}\text { Dongkeun Jun } & \text { https://orcid.org/0000-0001-9017-9929 } \\ \text { Yongseok Kwon } & \text { https://orcid.org/0000-0003-4584-797X } \\ \text { Jaehyun Bae } & \text { https://orcid.org/0000-0001-8716-3109 } \\ \text { Myungchul Lee } & \text { https://orcid.org/0000-0002-9721-0092 } \\ \text { Jeenam Kim } & \text { https://orcid.org/0000-0002-4080-6135 }\end{array}$

Hyungon Choi

Donghyeok Shin

https://orcid.org/0000-0002-3816-1286

https://orcid.org/0000-0002-8450-4411

\section{References}

1. Armstrong DG, Boulton AJM, Bus SA. Diabetic foot ulcers and their recurrence. N Engl J Med 2017;376:2367-75.

2. Brownrigg JR, Hinchliffe RJ, Apelqvist J, et al. Performance of prognostic markers in the prediction of wound healing or amputation among patients with foot ulcers in diabetes: a systematic review. Diabetes Metab Res Rev 2016;32 (Suppl 1): 128-35.

3. Jun YJ, Shin D, Choi WJ, et al. A mobile application for wound assessment and treatment: findings of a user trial. Int J Low Extrem Wounds 2016;15:344-53.

4. Oyibo SO, Jude EB, Tarawneh I, et al. A comparison of two diabetic foot ulcer classification systems: the Wagner and the University of Texas wound classification systems. Diabetes Care 2001;24:84-8.

5. Armstrong DG, Lavery LA, Harkless LB. Validation of a diabetic wound classification system: the contribution of depth, infection, and ischemia to risk of amputation. Diabetes Care 1998;21:855-9.

6. Everett E, Mathioudakis N. Update on management of diabetic foot ulcers. Ann N Y Acad Sci 2018;1411:153-65.

7. Hong JP, Oh TS. An algorithm for limb salvage for diabetic foot ulcers. Clin Plast Surg 2012;39:341-52.

8. Noor S, Khan RU, Ahmad J. Understanding diabetic foot infection and its management. Diabetes Metab Syndr 2017;11: 149-56.

9. McGuckin M, Goldman R, Bolton L, et al. The clinical relevance of microbiology in acute and chronic wounds. Adv Skin Wound Care 2003;16:12-23.

10. Broughton G 2nd, Janis JE, Attinger CE. Wound healing: an overview. Plast Reconstr Surg 2006;117(7 Suppl):1e-S-32e-S.

11. Kallio M, Vikatmaa P, Kantonen I, et al. Strategies for free flap transfer and revascularisation with long-term outcome in the treatment of large diabetic foot lesions. Eur J Vasc Endovasc Surg 2015;50:223-30. 